\title{
Gleaner-farmer relationships: A study of recruitment and relationship development
}

\author{
Sarah Lott ${ }^{\mathrm{a}}$ \\ University of Vermont \\ Emily Irwin b \\ Orleans County Natural Resources Conservation District \\ Sarah Heiss ${ }^{c *}$ \\ University of Vermont
}

\begin{abstract}
Submitted May 14, 2019 / Revised August 9 and November 21, 2019 / Accepted November 25, 2019 /
Published online April 7, 2020

Citation: Lott, S., Irwin, E., \& Heiss, S (2020). Gleaner-farmer relationships: A study of recruitment and relationship development. Journal of Agriculture, Food Systems, and Community Development, 9(3), 125-138. https://doi.org/10.5304/jafscd.2020.093.007
\end{abstract}

Copyright (C) 2020 by the Authors. Published by the Lyson Center for Civic Agriculture and Food Systems. Open access under CC-BY license.

\begin{abstract}
Food loss and waste is a significant issue in the global food system. The agricultural practice of gleaning - recovery and distribution of unharvested produce directly from farms or the recovery of unsold produce from farmers markets-is seen as a multifunctional intervention, with the potential to address food loss, food insecurity, and the reliance of food pantries on processed food. While research has identified food donation and food recovery programs such as gleaning as potential solutions to issues of food loss and food insecurity, more research is needed to examine the actual communicative organizing practices associated with food

a Sarah Lott, Graduate Student, Food Systems Master's Program, University of Vermont; Burlington, Vermont USA.

b Emily Irwin, Land Treatment Planner \& Nutrient Management Specialist, Orleans County Natural Resources Conservation District; Newport, Vermont 05855 USA.

c* Corresponding author: Sarah Heiss, Associate Professor, Department of Community Development and Applied Economics, University of Vermont; Morrill Hall 205; Burlington, Vermont 05406 USA; sarah.heiss@uvm.edu
\end{abstract}

recovery and gleaning efforts. With the aim of better conceptualizing the role that gleaning organizations might play in improving community food security and alleviating food loss, this study examines how gleaning programs develop and maintain relationships in emergency food systems. Based on 12 semistructured interviews with Vermont gleaning professionals, we aim (1) to describe the relationship between gleaning coordinators and farmers, with a focus on effective communication strategies for initiating and maintaining the relationship; and (2) to determine if participation in gleaning can add value to a farm enterprise. Results demonstrate the importance of farmers' sense of community responsibility and gleaners' individualized communication with farmers and knowledge of farming practices to the development and maintenance of gleaning relationships.

\section{Keywords}

Agriculture, Food Systems, Gleaning, Community Development, Food Insecurity, Communication, Food Waste, Onfarm Food Loss 


\section{Introduction and Literature Review}

Food loss and waste is a significant issue in the global food system. While there are well-documented concerns about the quality of food waste statistics (Bellemare, Çakir, Peterson, Novak, \& Rudi, 2017; Committee on World Food Security [CFS], 2014; Xue et al., 2017), the estimations are staggering: in 2011, an estimated 33\% of all food produced globally was lost or wasted (Food and Agriculture Organization of the United Nations [FAO], 2015; Gustavsson, Cederberg, Sonesson, van Otterdijk, \& Meybeck, 2011). The problem is particularly acute in developed countries such as the U.S. According to recent estimates, $40 \%$ of the food produced in the U.S. goes uneaten each year (Gunders, 2012). Food loss remains a challenge at the production level, as market prices are often not enough for farmers to offset the cost of harvesting and packaging their entire yields (Dunning, Johnson, \& Boys, 2019; Ishangulyyev, Kim, \& Lee, 2019). As a result, edible crops are left unharvested. For example, a sample of Vermont farmers in 2015 reported an estimated $16 \%$ of vegetables and $15 \%$ of berries were deemed "loss but salvageable" (Neff, Dean, Spiker, \& Snow, 2018). Developing strategies to address food loss, especially of fruits and vegetables at the production level, is important when $12.7 \%$ of U.S. households (15.8 million) are considered food insecure (Coleman-Jensen, Rabbitt, Gregory, \& Singha, 2016).

Food recovery and donation programs that capture food loss and distribute it to those in need have the potential to simultaneously address issues of food loss and food insecurity (Evans \& Nagele, 2018; Lee, Sönmez, Gómez, \& Fan, 2017; Neff, Kanter, \& Vandevijvere, 2015; Sönmez, Lee, Gómez, \& Fan, 2016). The practice of gleaningrecovery and distribution of unharvested produce directly from farms or the recovery of unsold produce from farmers markets - is seen as a multifunctional intervention, with the potential to address food loss, food insecurity, and the reliance of food pantries on processed food. Furthermore, gleaning programs, particularly those that are inclusive of the individuals that benefit from gleaned produce, can offer additional community benefits such as social support, empowerment, and improvement of community food security (Hoising- ton, Butkus, Garrett, \& Beerman, 2001). However, gleaning also operates in the context of the emergency food system, which has been widely criticized for failing to address the root causes of food insecurity (Tarasuk \& Eakin, 2005).

While research has identified food donation and food recovery programs such as gleaning as potential solutions to issues of food loss and food insecurity, more research is needed to examine the actual communicative organizing practices associated with food recovery and gleaning efforts. By developing a better understanding of how gleaning programs develop and maintain relationships in emergency food systems, we can better conceptualize what role they might play in contributing to community food security and alleviating food loss. Specifically, based on 12 semistructured interviews with Vermont gleaning professionals, we aim (1) to describe the relationship between a gleaning coordinator and a farmer, with a focus on effective communication strategies for initiating and maintaining the relationship; and (2) to determine if participation in gleaning can add value to a farm enterprise.

\section{Gleaning and Community Food Security}

Gleaning is collecting the food left in farm fields that is not economically or logistically feasible for the farmer to harvest (Beyranevand, LeasureEarnhardt, \& Valentine, 2015). Gleaning can also include collecting and donating excess food from farmers markets, packing lines, and storage houses (Beyranevand et al., 2015). Much of the literature written specifically about gleaning has focused either on how to quantitatively measure and maximize the impact of gleaning (Lee et al., 2017; Sönmez et al., 2016) or has examined the role of gleaning organizations in the communities they serve (Hoisington et al., 2001).

The community impact of gleaning is often analyzed through the critical lens of community food security (CFS). According to Hamm and Bellow (2003), the concept of CFS is defined by a systems approach: "[CFS] is defined as a situation in which all community residents obtain a safe, culturally acceptable, nutritionally adequate diet through a sustainable food system that maximizes community self-reliance and social justice" (p. 37). The concept 
of CFS encompasses more than the traditional definition of food security, which tends to focus on food access and affordability for low-income populations. Though the lens of community food security certainly focuses on issues of social justice and health, it also acknowledges the importance of fostering "civic agriculture," a concept first articulated by Thomas A. Lyson (2000): "a locally based agricultural and food production system that is tightly linked to a community's social and economic development" (p. 42).

Thus far, most studies using the lens of CFS have focused on the recipients of gleaned food in order to measure community impact. Gleaning programs can play an important role in the food system by distributing surplus produce to low income, food-insecure individuals. Most studies agree that gleaning improves diets by increasing access to local, fresh produce for individuals and food distribution sites (Berlin, Schattman, \& Hamilton, 2012; Hoisington et al., 2001; Neff et al., 2015; Vitiello et al., 2015). Some gleaning programs, particularly those run by food banks or those that directly involve food insecure populations in the practice of gleaning, have the potential to enhance communities' capacity to meet their own food needs, and serve to foster a sense of social empowerment (Hoisington et al., 2001; Vitiello et al., 2015).

In addition to empowering community members, there may be measurable benefits for the donors of gleaned food (Lee et al., 2017). The tangible financial advantages of food donation seem to depend heavily on the type of donor (food company or farm), the scale of the donor's operation, the total volume of donations, and whether the donor has knowledge of or access to financial incentives for donation, usually in the form of tax deductions or credits. Gleaning organizations and food security organizations have also suggested the potential for increased social capital among farmers who participate in gleaning and engage in "cause marketing" (i.e., marketing involvement in charitable programs in order to garner social capital), although again little empirical research has been done to support this (Neff et al., 2015).

However, the promotion of equity and social empowerment is not universal across gleaning pro- grams. In the context of gleaning, scale and inclusivity are two common CFS criticisms. Gleaning programs with access to large commercial farms result in more fresh produce in food bank distribution, but overlook and may unintentionally condone unsustainable farming practices and needless overproduction (Neff et al., 2015). Moreover, the reliance of gleaning programs on middle and upper-income volunteers can reproduce inequities in the emergency food and alternative food systems (Beischer \& Corbett, 2016; Berlin et al., 2012; Tarasuk \& Eakin, 2005; Vitiello et al., 2015).

\section{Relationships in the Context of Alternative Food Supply Chains}

It is clear that gleaning could play a role in reducing food loss and may, depending on the structure of the program, contribute to community food security. However, little has been written regarding the importance of social relationships-in particular, the relationship between gleaning organizations and farmers - in the success of a gleaning program. The contribution of strong social relationships to success in other areas of the alternative food supply chain, such as farm-to-institution, farm-toschool, and direct market sales, has been well documented (Buckley, Conner, Matts, \& Hamm, 2013; Conner, Sevoian, Heiss, \& Berlin, 2014; Heiss, Sevoian, Conner, \& Berlin, 2014; Izumi, Wynne Wright, \& Hamm, 2010; Kloppenburg et al., 2000). In addition, it is clear through anecdotal evidence that the success of gleaning rests largely on the strength of the relationship between a gleaning organization and an individual farmer (Martin \& Morales, 2014; Salvation Farms, 2018; Snow \& Dean, 2016; U.S. Department of Agriculture [USDA], 2010), although few scholars have empirically studied this relationship.

The importance of social relationships has become a recurring theme in alternative food systems literature, particularly in studies exploring farm-toinstitution (FTI) programs. For example, Conner et al. (2014) and Izumi et al. (2010) found that shared goals and values are important to FTI relationships between producers and buyers. Participation in FTI supply chains is motivated by shared values such as promoting good health, encouraging close relationships, and affirming the importance of edu- 
cation and community. Shared values were found to play a significant role in mediating relationships and resulted in mutual regard and desire to cooperate. Buckley et al. (2013) found that relationships based on trust and mutual support operate even throughout large and complex FTI networks, and that these close relationships encouraged creativity and adaptive problem-solving.

Gleaning organization guides and reports highlight the importance of strong relationships with farmers (Martin \& Morales, 2014; Snow \& Dean, 2016; Salvation Farms, 2018; USDA, 2010). For example, the guidebook produced by Salvation Farms, a Vermont gleaning organization, spends several paragraphs outlining best practices for maintaining relationships and communicating with farmers. Suggestions include, "Always follow through on your word, be sure to display your ethic for hard work, have dedication to your work and always be consistent and outwardly thankful" (Salvation Farms, 2018, p. 9). This would suggest that awareness of and respect for the farmer's business, as well as accountability, are vital to the success of the farmer-gleaner relationship.

Some gleaning guides and promotional materials even indicate that gleaning organizations provide a professional service to participating farmers. The prospectus of the Boston Area Gleaners (BAG, 2016), a document that consolidates the mission, goals, and achievements of the nonprofit, highlights a gleaning "success story" in which an eastern Massachusetts farmer saw a direct benefit from allowing gleaners on his farm. Because the price of tomatoes was so low, this farmer did not have a viable outlet for a bumper tomato crop. By harvesting his abundant tomatoes when the farmer could not afford to, the gleaners facilitated the continued production of his crop and allowed the farmer to wait until the tomato price recovered, and he could afford to harvest and sell his crop.

However, while professional resources exist to help gleaning organizations establish relationships and design messages to farmers, there is little empirical research on the nature of the relationships between gleaning organizations and farmers, and how exactly these relationships are established and maintained. In studying gleaning relationships, our research will contribute to a subject already identi- fied as important by the literature about alternative food systems and by gleaning professionals themselves. Further, by understanding the outreach strategies and messages used by gleaning coordinators to establish and maintain relationships with farmers, we will gain valuable insight into the potential role of gleaning to add value to a farm enterprise by enhancing overall community food security and reducing on-farm food loss.

\section{Methods}

Because of its number of gleaning organizations and the presence of a coordinating body, the Vermont Gleaning Collective, Vermont is an ideal location to study relationships between gleaning coordinators and farmers. The state's first formal gleaning program began in Burlington in 2004, and by 2015 eight regions in Vermont had communitybased gleaning programs (Schattman, Nickerson, \& Berlin, 2006). The Vermont Gleaning Collective, established by a large gleaning organization in 2013, is a statewide partnership of autonomous, community-based gleaning initiatives. The Collective staff focuses on providing guidance and technical assistance to gleaning coordinators, with the goal of cultivating professional, effective, and wellmanaged gleaning programs (Salvation Farms, 2018). Though the Collective includes several large gleaning organizations, there are some newer initiatives and a few long-established programs that are not members of the collective.

Although gleaning programs are thriving in Vermont, these programs also exist to address the familiar challenges of food loss on farms and to alleviate widespread food insecurity. A study done by Salvation Farms, a nonprofit focused on the management of agricultural surplus, found that on Vermont farms alone, an estimated 14.3 million pounds ( 6.49 million $\mathrm{kg}$ ) of vegetables and berries were lost each year (Snow \& Dean, 2016). At the same time, almost 30,000 Vermont households are food insecure, and lack access to enough food to meet basic nutritional needs (Coleman-Jensen et al., 2016). With the current gleaning infrastructure, food loss, and food security challenges, Vermont is an excellent place to explore relationships between gleaning organizations and farmers that involve these challenges. 


\section{Interviewee Recruitment}

After receiving approval from the University of Vermont Institutional Review Board, the authors used a purposive sampling technique to identify potential participants. We selected a sample that could provide us with multidimensional, information-rich perspectives on gleaning relationships with farmers (Polkinghorne, 2005). The twelve participants in our study represent nine of the ten gleaning programs currently operating in the state, and each participant plays a significant role in establishing and maintaining gleaning relationships

Table 1. Gleaning Coordinator Information

\begin{tabular}{llcccc}
\hline Name & Title & Age & Gender & $\begin{array}{c}\text { Gleaning } \\
\text { Coordinator } \\
\text { (years) }\end{array}$ & $\begin{array}{c}\text { Farm } \\
\text { Experience }\end{array}$ \\
\hline Irene & Local Food Access Coordinator & 25 & Female & 1.25 & Yes \\
Helen & Executive Director & 38 & Female & 14 & Yes \\
Emma & Branch Manager & 26 & Female & 2 & Yes \\
Abby & Gleaning and Food Rescue Coor- & 25 & Female & 3 & Yes \\
& dinator & 23 & Female & 2 & Yes \\
Amy & Gleaning Coordinator & 37 & Female & 3 & Yes \\
Lauren & Founding Director & 56 & Male & 0 & Yes \\
Ivan & Operations Manager & 22 & Female & 2 & Yes \\
Logan & NA & 22 & Female & 1 & No \\
Rebecca & Gleaning Coordinator & 30 & Female & 3 & Yes \\
Nora & Gleaning and Community Out- & & & & No \\
& reach Coordinator & 72 & Female & 5 & Yes \\
Rachel & Gleaning Volunteer Coordinator & 72 & Male & 0 & \\
Andrew & Executive Director & 37 & & &
\end{tabular}

between their organizations and local farmers.

All of our participants self-identified as white, and all but two were female. Interviewees ranged in age from 22 to 72 . Ten of the 12 had experience either working with farmers or in production agriculture prior to their current position. Most of the gleaners we interviewed were paid, full-time staff of Vermont nonprofits dedicated to food security and/or sustainable farming. Many of the gleaning coordinators were hired through the AmeriCorps Vista program. We only encountered two gleaning coordinators in Vermont who were not paid staff

members of an organization; one was a retired individual volunteering, and the other was a college student in a campus leadership role. Table 1 provides demographic information, position title, and experience for gleaning coordinators, and Table 2 provides information about their organizations.

A few organizations represented by participants were quite new and had been operating for less than one year.

Table 2. Gleaning Organization Information

\begin{tabular}{|c|c|c|c|c|c|c|}
\hline $\begin{array}{l}\text { Gleaning Coordina- } \\
\text { tor }\end{array}$ & Location & \# of Farmers & $\begin{array}{c}\text { \# of } \\
\text { Donation Sites }\end{array}$ & \# of Staff & \# of Volunteers & Lbs. Gleaned \\
\hline Irene & Rural & 29 & 14 & 1 & 164 & 34,250 \\
\hline Helen & Rural & 13 & 24 & 1 & 115 & 60,000 \\
\hline Emma & Rural & 80 & 300 & 2 & 1,000 & 400,000 \\
\hline Abby & Urban & 16 & 18 & 6 & 419 & 40,820 \\
\hline Amy & Rural & 10 & 18 & 2 & 19 & 10,600 \\
\hline Lauren & Rural & 30 & 15 & 1 & 280 & 30,000 \\
\hline Ivan & Rural & 12 & 60 & 2 & 100 & 82,480 \\
\hline Logan & Rural & 3 & 2 & 2 & NA & 260 \\
\hline Rebecca & Urban & 24 & 28 & 1 & 108 & 29,854 \\
\hline Nora & Urban & 15 & 150 & 4 & 250 & 471,000 \\
\hline Rachel & Rural & 10 & 55 & 2 & 140 & 78,000 \\
\hline Andrew & Rural & 25 & 60 & 1 & 150 & 200,000 \\
\hline
\end{tabular}

a $1 \mathrm{lb} .=0.45 \mathrm{~kg}$. 
Other gleaning programs were relatively well-established and had been gleaning for up to fifteen years. Some organizations belonged to the Vermont Gleaning Collective, while others either did not know about the collective or had chosen to operate outside of the collective. Gleaning programs also differed in organizational capacity: organizations worked with three to 80 farmers, two to 300 recipient sites, engaged 19 to 1,000 volunteers, and gleaned 260 to 471,000 pounds (118 to $214,000 \mathrm{~kg}$ ) of produce through in-field gleaning, on-farm pickups and farmers market collections in 2016 alone.

This diversity of informants gave us a comprehensive view of the process of relationship-building with local farmers. While we interviewed three participants from the same organization, these three informants represent a particularly large gleaning organization. In addition, each informant brought a unique perspective to our study of farmer-gleaner relationships, in terms of their experiences working with farmers, caseloads, and professional background prior to gleaning.

\section{Semistructured Interviews}

We prepared a semistructured interview guide to provide some structure for the interviews, but we also adapted the questions to fit the experience of each participant (Lindlof \& Taylor, 2011). Our two primary questions focused on the types of things gleaning coordinators said or did to initiate and maintain gleaning relationships. Though we did ask a third primary question about what might cause a gleaning relationship to deteriorate, we found that most participants had not experienced the deterioration of a gleaning relationship. Primary questions were nondirective, allowing the subject to define the scope of his or her answer (Lindlof \& Taylor, 2011). In follow-up probes, the interviewers attempted to clarify statements or stories, and elicit examples of specific relationships that might demonstrate the process of relationship-building in practice. Each researcher conducted six interviews. To maintain consistency, the researchers met frequently during data collection to discuss interview experiences and emerging themes. The interviews were audio-recorded and immediately transcribed verbatim. All names and identifying information were replaced with pseudonyms in order to main- tain the confidentiality of interviewees and their respective organizations.

\section{Thematic Analysis}

Thematic analysis is a qualitative technique used to identify, analyze, and report patterns or themes within data (Braun \& Clarke, 2006). Initially, both researchers read and coded the entire dataset separately. This process yielded several codes and themes within the data. We then worked together to engage in focused coding to identify broader underlying themes that were reoccurring across participants and across researchers' codes.

\section{Analysis}

As gleaning coordinators emphasized the importance of setting up professional relationships with farmers, we will first describe the primary characteristics of a professional gleaner-farmer relationship. In addition, several interviewees observed that farmers participated in gleaning to contribute to their community, broaden access to local food, and reduce on-farm food loss. We found that the gleaner-farmer relationship facilitated the farmer's expression of community values and alleviated some of the guilt associated with onfarm food loss.

\section{Attributes of a Professional Gleaner-Farmer Relationship}

Gleaning coordinators focused on establishing professional relationships with farmers. As participants described characteristics of successful gleanerfarmer relationships, two main themes emerged, that the relationships were grounded in trust and a farmer-centered process.

Trust. Interviewees stressed the importance of establishing trust with a farmer. Some gleaners established this trust by emphasizing their experience with production agriculture. For the farmer, knowing that a gleaner was comfortable with harvesting helped ease the anxiety that can come from hosting a group of volunteers in their fields. When initiating a relationship with a farmer, Emma stressed, it was important "that we're really careful, that we're trained farmers who know what we're doing and have ... all the equipment that we need. Basically that we're a self-sufficient operation once we're on 
the farms." Emma found that highlighting her own agricultural experience was critical to establishing trust with a farmer. Logan also found that when she communicated her agricultural knowledge to a farmer, she felt that, "The farmers ... have more trust in what's going on and kinda leave us alone while we're gleaning." If a farmer knew that Logan had the necessary skills to lead a crew and harvest responsibly, the farmer trusted that the gleaning group would complete their task and leave everything else as they had found it.

In addition to emphasizing their overall agricultural competence, several gleaning coordinators mentioned the importance of learning about each farm operation. Interviewees found that expressing an interest in the farm enterprise beyond the details necessary for a successful gleaning event was important to establish a good working relationship. Irene spoke of a "communication investment of [sic] what their farm is doing. Not necessarily even related to gleaning ... asking what their farm operation is." Irene tried to understand the structure of the farm enterprise, including crops cultivated, market channels, and level of mechanization. Although she did not necessarily need these details to organize gleaning events, with this "communication investment," Irene demonstrated that she was invested in the farm business beyond the pounds of produce donated to her organization. Rachel also remarked that being familiar with a farm's current regulatory challenges, such as complying with federal food safety laws, was part of cultivating a good relationship. She continued, "I'm interested in it [the new food safety laws], and it certainly helps me to be more appreciative and, you know, kind of knowing why they do what they do and so forth." Helen summed up the importance of understanding production agriculture and demonstrating a commitment to the farm:

If you can't prove to them [the farmer] that you understand their farm business, that you understand farm operations and the realities that farmers face every day ... you know they may engage, but I think they aren't going to feel... you know, a full sense of security and trust that you are going to do right by their farm on many levels.
If a gleaner highlighted her agricultural knowledge and her commitment to the farm as a business, then a farmer could trust that the gleaner and her volunteers would harvest un-marketable produce with respect for his potentially marketable crops nearby.

Several gleaning coordinators also mentioned that visiting farms, particularly at the beginning of a relationship, was an important part of establishing trust. A farm visit offered the opportunity to understand the farm operation further, and allowed the gleaner to gather important details related to gleaning. When asked why she visited farms at the beginning of a gleaning relationship, Amy said, "I think it's great for relationship building, just meeting them face-to-face. And it's also a time for them to show us their operations... and just, I think it's really mostly relationship building, and building that trust with people." By taking the time to visit the farm at the beginning of a relationship, Amy demonstrated her commitment to the farmer and his business. Amy's goal was to build trust in herself and her organization so that when she came to the farm to glean, the farmer could trust that she and her volunteers would respect the farm business.

Gleaners also visited farms not only at the beginning of a relationship but at the beginning of each season to gather the details necessary for a successful gleaning event. Through their attention to detail, gleaners demonstrated to the farmer their commitment to supporting the business as a whole. At the beginning of any relationship with a farm, Lauren tried to "visit that farm ahead of time, just so I get a feeling for like, you know, where things are, where we would park ... those kinds of things." Similarly, Rachel sought to "make a visit to see what it is and to see what the scene is and how we would work there and so forth; just make a personal contact." Abby said that she often visited established gleaning farms at the beginning of each season, "to have them [the farmers] show me where I'm going to be going, and . . . where to drive when we're on the field, and these are where the pipes are. Just to get the lay of the land." By visiting and getting to know the details of the farm operation, gleaning coordinators demonstrated to the farmer that they took their positions seriously, 
and wanted to make sure they did not negatively impact other aspects of the farm business during gleaning events.

Farmer-centered process. Farmers and gleaners worked together to design a gleaning schedule and a communication routine that fit within a farmer's needs. Several gleaning coordinators mentioned the importance of emphasizing the overall flexibility of the gleaner-farmer partnership. When introducing gleaning to farmers, Amy explained that gleaning "could be as simple as we can arrange it." She continued, "you can text me on Monday and then on Wednesday we can come out with groups of people for two hours." To fit gleaning into a farmer's busy schedule, Amy tried to be as flexible as possible, even if it meant scheduling gleans just two days ahead of time. Nora also tried to stress the ease of incorporating gleaning into a farm operation. She remarked, "I try to say how flexible it is...there's never any pressure. And I just try to really implement consistency and ease." Nora sought to conduct her relationship with farmers "like a customer service relationship." Gleaning coordinators described working with farmers based on the needs of the business, and making the gleaning process and communication routines as easy as possible. Helen aimed at designing "a partnership that works for them, at their comfort level." Gleaning coordinators recognized that no matter how well-organized they were, participation in gleaning required extra effort for a farmer. Because they understood production agriculture, gleaners also knew that farmers did not have extra time to dedicate to gleaning. To address this, gleaning coordinators highlighted the flexibility of the gleaner-farmer relationship, and focused on designing a process and communication routine that worked for the farmer.

Some participants found that the most successful partnerships involved setting up a consistent weekly glean for a farm. Andrew pointed out that "consistency and routine is, like, the bread and butter of a farmer.... and so we've worked to provide that to them." Andrew explained that many farmers make a rough plan at the beginning of each week. If gleaning is on a farmer's schedule, they can integrate it into their weekly plan. Andrew pointed out that a consistent weekly gleaning schedule was also beneficial for his organization. He explained that if he just sent an email to all the farmers in the area, introducing the idea of gleaning and asking the farmer to get in touch if they had anything to offer, farmers would be too busy to respond. If farmers integrated gleaning into their weekly plan, then his organization could count on produce to distribute from that farm each week. Similarly, Abby observed that if she set up a weekly glean, "that farmer knows ... OK, I could till this in and plant something new today. But, Abby's coming tomorrow, I'll do something else this afternoon, and I'll till that in after Abby leaves." With an established weekly glean, farmers could easily integrate gleaning into their operations, and gleaning organizations could count on a relatively consistent supply of produce.

Gleaners also established consistency in their communication practices with farmers. The specific mode of communication depended on the needs of the farmer, but could include text messages, email, phone calls, and/or in-person. Abby, who has standing weekly gleans with a few farmers, explained that "after that first initial email, week of gleaning, then it becomes mostly just text messages.” She continued, “. . . I'll send a text message the night or two before, usually the night before, saying, 'still planning on coming tomorrow, sounds good, is there a place I should meet you?"' A consistent texting schedule was the most convenient communication routine for the farmer, so Abby adopted the farmer's desired mode of communication. Like Abby, Rebecca also coordinated weekly gleans. She described her communication routine with one farm as less regular than the routine Abby described. While Rebecca has a standing weekly glean at a particular farm on Thursdays, sometimes, she said, "[The farmer] might text me and be like, 'We're tilling this row, do you want to come out Monday afternoon and just glean super quick to get it?"' The combination of last-minute gleans and a standing weekly glean worked for this farmer, so Rebecca adapted to this communication routine, although she wasn't always able to harvest at the last minute. Rebecca indicated that she communicated with farmers based on what worked for their business. Describing her pick-up schedule at a large farm's farm stand: “They're busy so I just try and 
get out so that they don't have to think about it, and just take it and go; because that's what fits their business model, which is fine." Similar to other gleaning coordinators, Rebecca was flexible in her communication and the design of her farm partnership in order to meet the needs of the farm.

\section{Gleaning Adds Value}

The gleaner-farmer relationship can also add value to an agricultural enterprise by providing a way for a farm business to express its values. While there are a variety of motivations for farmers to participate in gleaning, interviewees regularly mentioned values as a driving force for participation. Two values were mentioned as being fundamental: contributing to the community and reducing food loss on the farm.

Contributing to the community. Several interviewees said that for many farmers, participation in gleaning was a way for them to give back to their communities and address inequities in food access. Abby, a gleaning coordinator for an organization with a few long-term gleaning partners, said of one farm, "They have a huge food justice component to their farm's mission statement ... so they're just really committed to feeding their neighbors." This farm was dedicated explicitly to providing access to good food for all community members, so participation in gleaning was an obvious way for them to fulfill this mission. Logan, a gleaning coordinator for a relatively new organization, described farmers' feelings of community obligation in more personal terms: "They all . . . are part of the community, have friends in the community, and want to do their part to share any surplus that they have." In Logan's experience, many farmers recognize that food security is "a major problem that needs addressing," and are committed to donating their surplus. For some farms, the desire to give back to their community was part of their mission, while for other farms, the desire to give back to their community was driven by a sense of obligation.

A few interviewees also spoke of the responsibility that farmers felt to contribute to the community, specifically because not everyone was able to afford their produce. Andrew, a key figure in a large gleaning organization:
To be honest, local farms in our area ... for the most part...their products are usually more expensive ... So there's ... I guess you would say a social justice mission there of providing good food for everybody no matter whether they can afford it or not.

Although farmers in this region of Vermont felt that they needed to sell their products at a higher price to remain viable as a business, in Andrew's experience, most farmers recognized that not all members of their community could afford their products. Rachel, another critical figure in the same organization, said that farmers recognize that “. . . a lot of the people can't afford to buy their food, and they feel that they want to support the community ... if they donate to [the gleaning organization], they're supporting the community in that way." Similarly, Helen framed gleaning as a way to provide "... food to people that have limited access and need to have a cost-free opportunity to explore with fresh foods." In the experience of gleaning coordinators, participation in gleaning allowed farmers to help alleviate unequal access to local produce.

While gleaners recognized farmers' sense of responsibility and helped them to express their community values through gleaning, they also made sure that the gleaner-farmer relationship remained professional, and did not rely solely upon the farmer's altruism. For example, Irene said that when she approached a farmer, she tried to underscore that she understood,

that this [gleaning] is not some mushy-gushy charity case work for you, that ... yes, you see a need and that is why you're doing it, and you want to help the community, but at the end of the day, you have to get a job done. And I want to show you that, you know, this can, can fit within what your needs are.

Irene's approach recognized that many farmers were motivated by community values, but also demonstrated that she understood the extra effort required to participate in gleaning. Irene did not approach farmers as a nonprofit representative seeking donations; rather, she introduced gleaning 
to farmers as a professional service that could offer their surplus to people in need. Emma also acknowledged that although farmers often wanted to donate their surplus produce, it was most important for her to emphasize the competency and professional nature of her organization. Emma described the most effective approach:

... highlighting your own farming experience, trying to make them comfortable with you being at their farm. Because if you sort of approach it as like, "I work for this nonprofit, we're all about charitable food ..." Yeah, everybody can buy into that, but it doesn't ease the feeling of having strangers on your property picking your food.

Gleaning coordinators recognized that many farmers had a desire to contribute to their community. However, most did not emphasize this aspect of participation in gleaning. Instead, coordinators underscored the professional characteristics of the relationship they sought to establish with farmers in order to meet their shared goal of serving their community.

Reducing food loss. In addition to farmers' desire to contribute to their communities, interviewees also noticed that many farmers wanted to participate in gleaning because they did not like to see their product, something that they had put time and money into growing, go uneaten. When asked why farmers participate in gleaning, Rebecca said:

When I've spoken with farmers, it's like... "We grew it ... and it looks great and I see it rotting in the field, and I know there's people that need it. And we don't have the capacity to harvest it or the market to sell it, and we just want to see ... someone using it."

In a perfect world, farmers would be able to sell everything they grew. In reality, due to a wide variety of constraints, this is rarely possible. Nora, a gleaning coordinator for a different organization, saw participation in gleaning as a simple way to put excess produce to good use: "I think no one likes to see vegetables go bad. We're the easy way to gather those vegetables, then I think [the farmers are] usually happy to participate." Emma, a coordinator for the same organization, summarized: "To be able to rely on a gleaning organization to come in on a scheduled basis and handle that entity for you, it removes so much of the guilt associated with food loss and food waste." According to gleaning coordinators, both farmers and gleaners do not want to see edible surplus in the field go uneaten. Many farmers take advantage of gleaning programs to reduce on-farm food loss.

Although most gleaning coordinators stated that farmers did not like to see their food go uneaten, a few had mixed feelings about emphasizing the ability of gleaning to reduce food loss. In particular, Andrew felt strongly about not framing surplus produce as "waste":

Especially in the farm's case, it's not wasted, it's nutrients, it's going back to the soil, it's being composted ... there is a benefit to the farm in keeping it there ... of course, the highest and best use of the food would be as food. So ... they see it as ... an opportunity to have more of a value to the community at least by giving it away.

While Andrew acknowledged the ability of gleaning to reduce on-farm food loss, he did not see this as the most important motivation for participation in gleaning. Instead, he was careful to frame gleaning as a way to add value to surplus produce by offering it to community members in need. Several other gleaning coordinators recognized a tension in the idea that participation in gleaning could help reduce food loss on farms. Abby said, "Occasionally [a farmer she has worked with] has stuff that he can't keep up with ... I think his mindset is like, I'm inviting gleaners on my farm, that is a crop that I put money into that I've lost. And it's a bummer for him." Abby recognized that agricultural surplus was not necessarily a positive thing for farmers. A farmer plants and cultivates a crop with the intention of selling it. To a farmer, surplus represented a loss of time and money invested. Gleaning coordinators observed that some farmers did not see agricultural surplus as waste at all, while other farmers saw surplus as a crop that they were not able to sell. When surplus 
did occur, participation in gleaning helped to reduce some of the associated guilt by allowing a farmer's hard work to go to its highest use-feeding people.

\section{Discussion}

Gleaning coordinators focused on setting up professional relationships with farmers. They began by establishing trust with a farmer and tried to define a process and a communication routine based on the needs of the farmer. In addition, gleaning coordinators found that once a successful relationship was established, participation in gleaning could provide several services for the farmer, many of them indirect. However, in the experience of the gleaning coordinators whom we interviewed, the primary reasons that farmers participated in gleaning were to contribute to values shared by farm enterprises and gleaning organizations: contributing to the community and reducing on-farm food loss. The ability of farmers to express these shared values was based largely on the strength of the relationship between the gleaning organization and the farmer. Although gleaning coordinators acknowledged that community values and food loss reduction were primary motivations, most gleaning coordinators chose to emphasize the professional nature of their organization and gleaning process.

The implications of our analysis are relevant to many geographical contexts beyond our sample in Vermont and make an important contribution to broader conversations about food waste solutions. Nationwide, gleaning organizations are valuable for the opportunity to reduce both food waste and food insecurity in communities (Hoisington et al. 2001). The gleaner-farmer relationship is at the crux of facilitating this process and, without respecting and understanding the importance of those relationships, the opportunity could be lost.

\section{Theoretical Contributions}

Our study found that the ability of farmers to contribute to their community and reduce on-farm food loss through gleaning is facilitated by the professional nature of the gleaner-farmer relationship. Through this relationship, a gleaning coordinator creates a farm-centered process through which a farmer can contribute to the community and re- duce on-farm food loss. The primacy of social relationships in gleaning echoes the work done by scholars in the realm of farm-to-institution supply chains (Buckley et al., 2013; Conner et al., 2014; Heiss et al., 2014) and farm-to-school (Conner et al., 2012; Izumi et al., 2010), and reflects the emphasis more generally on social relationships as an important component of the alternative food system (Kloppenburg et al., 2000; Lyson, 2000). Conner (2014) and Izumi (2010) also recognized supporting community as an important shared value of members of the FTI supply chain. Both gleaners and farmers value community, and farmers rely on the professional relationship created with gleaning organizations to express this value.

\section{Practical Implications}

Our study provides several practical implications for the future of gleaning. First, we offer empirical evidence for advice that already has been documented anecdotally: the importance of a professional gleaner-farmer relationship. Participants described successful and productive relationships with farmers as based on trust, flexible processes, and farmer-centered communication. Gleaning coordinators should continue to establish clearly defined professional relationships with farmers. Beyond the characteristics of the professional relationship outlined in gleaning guides, coordinators should demonstrate agricultural knowledge and commitment to the success of the farm enterprise. Gleaners should also focus on setting up a unique process and communication routine that fits the needs of each particular farm.

Participants also agreed that farmers were motivated to participate in gleaning by community values, and by a desire to see their surplus go to its highest use-food for people. However, few gleaning coordinators explicitly linked these concepts, and pitched participation in a professional gleaning relationship as a way for farmers to contribute easily to the community. Some gleaning coordinators highlighted the potential community contribution in initial discussions with farmers, and a few discussed advertising farm participation. Gleaning coordinators should draw a clear connection between a farmer's desire to contribute to the community, and the ease and professional nature of a gleaner- 
farmer relationship. Further, coordinators should explore ways to market farm participation in gleaning so that the community is aware of their contribution. In addition, it was clear that in the experience of gleaning coordinators, as well as in general, that farmers respond differently to the idea of agricultural surplus as food loss or waste (Beausang, Hall, \& Toma, 2017). Regardless of farmer opinion on this topic, gleaning coordinators can also emphasize participation in a professional gleaner-farmer relationship as a way for a farmer to ensure that their surplus goes to its best use, as food.

Second, scholars have discussed the efficacy of financial incentive policies to support increased food donations through gleaning (Lee et al., 2017). However, while financial incentives would likely be helpful, according to our research they are not the perceived primary factor that drives participation in gleaning. Rather, as gleaning coordinators report, farmers are busy, and current federal tax deductions are difficult to navigate. Thus, regardless of financial incentives, farmers are driven already to participate in gleaning by a sense of community obligation. This indicates that financial incentives for participation may not be needed on the farmer side. Resources and infrastructure should, therefore, be directed towards gleaning organizations themselves, as has been suggested by other research (Lee et al., 2017). Improved infrastructure and staffing would allow gleaning organizations to set up even more professional, consistent relationships with farmers. In addition, gleaning organizations would be able to more thoughtfully market farmer participation and communicate information to farmers about produce recipients.

\section{Limitations}

There are several limitations to our analysis. First, results speak to the experiences of gleaner-farmer relationships; however, only the experiences of the gleaners were collected for this study. In sections of the analysis, gleaners provide their perspective on how farmers view gleaning organizations and how they may value the relationship. To fully understand the gleaner-farmer relationship, future research should interview farmers for a first-hand account of their experiences.

An additional limitation to our study is the lack of demographic variability among study participants. Most of the gleaning coordinators were female and in their 20s and 30s. Most gleaning coordinators in Vermont have some previous farm experiences, which may allow them to anticipate better the needs and expectations of farmers they work with than many gleaners in the U.S. The homogeneity of participants is consistent with the larger population of Vermont but may exclude backgrounds of many of those who participate in gleaning nationwide.

\section{Conclusions}

While gleaning has the potential to provide a number of services to farms, this study found that gleaners perceived participation in gleaning programs as being motivated by shared community values. Specifically, gleaners observed that farmers were motivated by a desire to improve community food security and reduce on-farm food loss. A partnership with a professional gleaning organization is an easy way for a farmer to express these values. This nontraditional understanding of farmer motivation builds upon the importance of community values and social relationships in local food systems. It is our hope that policymakers and future researchers continue to explore the viability of the role of gleaning in the alternative food systems.

\section{References}

Beausang, C., Hall, C., \& Toma, L. (2017). Food waste and losses in primary production: Qualitative insights from horticulture. Resources, Conservation and Recycling, 126, 177-185. https://doi.org/10.1016/j.resconrec.2017.07.042

Bellemare, M. F., Çakir, M., Peterson, H. H., Novak, L., \& Rudi, J. (2017). On the measurement of food waste. American Journal of Agricultural Economics, 99(5), 1148-1158. https://doi.org/10.1093/ajae/aax034

Berlin, L., Schattman, R., \& Hamilton, J. (2012). Working toward the common table: The policy and program implications of Vermont's unified approach to social justice, food insecurity, and local food. Journal of Hunger \& Environmental Nutrition, 7(4), 426-435. https://doi.org/10.1080/19320248.2012.732916 
Beyranevand, L. J., Leasure-Earnhardt, A., \& Valentine, R. (2015). The National Gleaning Project: Guide to the online gleaning resources bub. South Royalton, VT: Center for Agriculture and Food Systems, Vermont Law School. Retrieved from https://nationalgleaningproject.org/wp-content/uploads/2018/12/NGP-online-gleaning-resources-hub.pdf

Boston Area Gleaners. (2016). Boston Area Gleaners prospectus. Boston, MA: BAG. Retrieved from http://www.bostonareagleaners.org/uploads/1/6/4/6/16465104/bag prospectus 2016.pdf

Braun, V., \& Clarke, V. (2006). Using thematic analysis in psychology. Qualitative Research in Pyschology, 3(2), 77-101. https://doi.org/10.1191/1478088706qp063oa

Buckley, J., Conner, D. S., Matts, C., \& Hamm, M. W. (2013). Social relationships and farm-to-institution initiatives: Complexity and scale in local food systems. Journal of Hunger \& Environmental Nutrition, 8(4), 397-412. https://doi.org/10.1080/19320248.2013.816988

Coleman-Jensen, A., Rabbitt, M. P., Gregory, C. A., \& Singha, A. (2016). Household food security in the United States in 2015 (Economic Research Report No. 215). Washington, DC: U.S. Department of Agriculture, Economic Research Service. Retrieved from https://www.ers.usda.gov/webdocs/publications/79761/err-215.pdf

Committee on World Food Security (CFS). (2014). Food losses and waste in the context of sustainable food systems. A report by the High Level Panel of Experts on Food Security and Nutrition of the Committee on World Food Security (HLPE Report No. 8). Rome: CFS \& Food and Agriculture Organization of the UN (FAO). Retrieved from http://www.fao.org/3/a-i3901e.pdf

Conner, D., King, B., Kolodinsky, J., Roche, E., Koliba, C., \& Trubek, A. (2012). You can know your school and feed it too: Vermont farmers' motivations and distribution practices in direct sales to school food services. Agriculture and Human Values, 29(3), 321-332. https://doi.org/10.1007/s10460-012-9357-y

Conner, D. S., Sevoian, N., Heiss, S. N., \& Berlin, L. (2014). The diverse values and motivations of Vermont farm to institution supply chain actors. Journal of Agricultural and Environmental Ethics, 27(5), 695-713. https://doi.org/10.1007/s10806-013-9485-4

Dunning, R. D., Johnson, L. K., \& Boys, K. A. (2019). Putting dollars to waste: Estimating the value of on-farm food loss. Choices, 34(1), 1-3. Retrieved from http://www.choicesmagazine.org/choices-magazine/themearticles/examining-food-loss-and-food-waste-in-the-united-states/putting-dollars-to-waste-estimating-the-value-ofon-farm-food-loss

Evans, A. I., \& Nagele, R. M. (2018). A lot to digest: Advancing food waste policy in the United States. Natural Resources Journal 58(1), 177-214. Choices 34(1), 1-9. Retrieved from https://www.jstor.org/stable/26394778

Food and Agriculture Organization of the United Nations (FAO). (2015). Food wastage footprint \& climate change. Rome: FAO. Retrieved from http://www.fao.org/3/a-bb144e.pdf

Gunders, D. (2012). Wasted: How America is losing up to 40 percent of its food from farm to fork to landfill (NRDC Issue Paper IP:12-06-B). New York: Natural Resources Defense Council. Retrieved from https://www.nrdc.org/sites/default/files/wasted-food-IP.pdf

Gustavsson, J., Cederberg, C., Sonesson, U., van Otterdijk, R., \& Meybeck, A. (2011). Global food losses and food waste: Extent, causes and prevention. Rome: Food and Agriculture Organization of the UN. Retrieved from http://www.fao.org/docrep/014/mb060e/mb060e.pdf

Hamm, M. W., \& Bellows, A. C. (2003). Community food security and nutrition educators. Journal of Nutrition Education and Behavior, 35(1), 37-43. https://doi.org/10.1016/S1499-4046(06)60325-4

Heiss, S. N., Sevoian, N. K., Conner, D. S., \& Berlin, L. (2014). Farm to institution programs: Organizing practices that enable and constrain Vermont's alternative food supply chains. Agriculture and Human Values, 32(1), 87-97. https://doi.org/10.1007/s10460-014-9527-1

Hoisington, A., Butkus, S. N., Garrett, S., \& Beerman, K. (2001). Field gleaning as a tool for addressing food security at the local level: Case study. Journal of Nutrition Education, 33(1), 43-48. https://doi.org/10.1016/S1499-4046(06)60009-2

Ishangulyyev, R., Kim, S., \& Lee, S. H. (2019). Understanding food loss and waste-Why are we losing and wasting food? Foods, 8(8), 297. https://doi.org/10.3390/foods8080297 
Izumi, B. T., Wynne Wright, D., \& Hamm, M. W. (2010). Market diversification and social benefits: Motivations of farmers participating in farm to school programs. Journal of Rural Studies, 26(4), 374-382. https://doi.org/10.1016/j.jrurstud.2010.02.002

Kloppenburg, J., Lezberg, S., De Master, K., Stevenson, G., \& Hendrickson, J. (2000). Tasting food, tasting sustainability: Defining the attributes of an alternative food system with competent, ordinary people. Human Organization, 59(2), 177-186. https://doi.org/10.17730/humo.59.2.8681677127123543

Lee, D., Sönmez, E., Gómez, M. I., \& Fan, X. (2017). Combining two wrongs to make two rights: Mitigating food insecurity and food waste through gleaning operations. Food Policy, 68, 40-52. https://doi.org/10.1016/i.foodpol.2016.12.004

Lindlof, T. R., \& Taylor, B. C. (2011). Qualitative communication research methods (3rd ed.). Thousand Oaks, CA: Sage.

Lipinski, B., Hanson, C., Lomax, J., Kitinoja, L., Waite, R., \& Searchinger, T. (2013). Reducing food loss and waste (Installment 2 of Creating a sustainable food future). Washington, DC: World Resource Institute. Retrieved from https://www.wri.org/publication/reducing-food-loss-and-waste

Lyson, T. A. (2000). Moving toward civic agriculture. Choices, 15(3), 42-45. https://doi.org/10.22004/ag.econ.132154

Martin, K., \& Morales, T. (2014). Growing connections: A resource guide for farm-to-food bank strategies. Seattle: Northwest Harvest. Retrieved from https://www.northwestharvest.org/resource-guides

Neff, R. A., Dean, E. K., Spiker, M. L., \& Snow, T. (2018). Salvageable food losses from Vermont farms. Journal of Agriculture, Food Systems, and Community Development, 8(2), 39-72. https://doi.org/10.5304/jafscd.2018.082.006

Neff, R. A., Kanter, R., \& Vandevijvere, S. (2015). Reducing food loss and waste while improving the public's health. Health Affairs, 34(11), 1821-1829. https://doi.org/10.1377/hlthaff.2015.0647

Polkinghorne, D. E. (2005). Language and meaning: Data collection in qualitative research. Journal of Counseling Psychology, 52(2), 137-145. https://doi.org/10.1037/0022-0167.52.2.137

Salvation Farms. (2018). Community-based gleaning: A bow-to guide prepared by Salvation Farms. Morrisville, VT: Salvation Farms. Retrieved from http://www.salvationfarms.org

Schattman, R., Nickerson, V., \& Berlin, L. (2006). Farm to plate: Strengthening Vermont's food system. Montpelier, V'T: Vermont Sustainable Jobs Fund. Retrieved from http://www.vtfarmtoplate.com/assets/plan_sections/files/4.1\%20Food $\% 20$ Security $\% 20$ in $\% 20$ Vermont_Feb $\% 20$ 2015_small\%20file.pdf

Snow, T., \& Dean, E. (2016). Food loss in Vermont: Estimating annual vegetable \& berry loss. A Salvation Farms' analysis. Morrisville, VT: Salvation Farms. https://salvationfarms.org/VT Food Loss Study 2016.pdf

Sönmez, E., Lee, D., Gómez, M. I., \& Fan, X. (2016). Improving food bank gleaning operations: An application in New York State. American Journal of Agricultural Economics, 98(2), 549-563. https://doi.org/10.1093/ajae/aav069

Tarasuk, V., \& Eakin, J. M. (2005). Food assistance through "surplus" food: Insights from an ethnographic study of food bank work. Agriculture and Human Values, 22(2), 177-186. https://doi.org/10.1007/s10460-004-8277-x

U. S. Department of Agriculture. (2010). Let's glean! United we serve toolkit. Washington, DC: USDA. Retrieved from https://www.usda.gov/sites/default/files/documents/usda gleaning toolkit.pdf

Vitiello, D., Grisso, J. A., Whiteside, K. L., \& Fischman, R. (2015). From commodity surplus to food justice: food banks and local agriculture in the United States. Agriculture and Human Values, 32(3), 419-430. https://doi.org/10.1007/s10460-014-9563-x

Xue, L., Liu, G., Parfitt, J., Liu, X., Van Herpen, E., Stenmarck, Å., ... \& Cheng, S. (2017). Missing food, missing data? A critical review of global food losses and food waste data. Environmental Science \& Technology, 51(12), 6618-6633. https://doi.org/10.1021/acs.est.7b00401 